\title{
Mar de los chilenos
}

Al amparo de viejas velas, cangrejas húmedas de Chiloé o cuadras parchadas del Maule, he cruzado tu salvaje soledad, mar de los chilenos, y he bebido tu hálito salobre, hermano del puelche de las nieves y del acre aliento de los pehuenes.

Mar de Chile, inmenso y virgen, que no hendieron griegos mascarones, ni supo de velas de púrpura ni de gavieros expertos, sino de balsas de cuero o trenzadas velas de totora, pero bebió el alma multisonora de los vientos primitivos.

Piraguas de centenarios troncos, rápidos bongos de las islas o canoas de cuero de los mares australes, fluctuantes como el pensamiento de sus pilotos, rompieron tus olas, huyendo del trueno, bajo la cabalgata de las nubes y vientos de aventura, desde el otro extremo del mundo, empujaron las velas rapaces de los piratas de Inglaterra y Holanda, trágicamente incorporados a la leyenda del mar chileno.

Mar del Norte, hijo del sol, cuya verde entraña se torna nieve espumosa al romperse en los grises acantilados, muro del desierto ubérrimo. Mar rayado por el vuelo negro de los yecos y el pestañeo de las garumas y roto por la daga de las albacoras.

Mar del centro de Chile, blanco de gaviotas, hirviente de congrios atigrados, de róbalos de plata y cabinzas de ojos sajones. Mar de los viejos pescadores coloniales, ingenuos y supersticiosos.

Mar amigo de la cordillera que baja en las venas de sus ríos, empapados de altura, a teñir el verdor de las olas de azules transparencias. 
¡Mar del Maule, destrozado como un cristal en las aristas de las peñas, forradas de algas, erizadas de moluscos como cascos muertos!

Del corazón de tus cerros bravíos, tierra hecha piedra, bajan las rodas de roble en carretas minúsculas, y sobre ellas, el serrano mudo, piedra hecha carne, vuelto marino ante el estupor del mar nunca soñado, heroico en la caña que acaba de empuñar, como en la mancera de sus viejos arados de hualle.

Mar de Chiloé, extraviado entre islotes de esmeralda, espejo ávido de las selvas oscuras, de los verdeantes papales y de los villorrios grises, sumisos en torno a un campanario de madera. Mar amado del gran mar que en violentas crecientes, tarde y mañana, derrama su sangre salobre en la pasiva quietud de los canales.

Una mortaja de nieblas espesas arrebuja en los inviernos los cerros ateridos y las aguas muertas, donde navega el Caleuche, hinchadas de aire las velas espectrales y su casco acribillado de luces: allí la imaginación del chilote, niebla y estupor, inmortalizó a los ahogados, a los piratas vencidos, a todos los que murieron en lucha con el mar.

Lanza de oro, el sol quiebra en los estíos tu cristal hecho de ascuas y va a teñir, empapado en sangre de auroras o en púrpura de arreboles, la coraza de las centollas, dormidas en la penumbra del remanso submarino.

La paleta de ciprés del huilliche partió, en lejanas edades, tu espejo dormido, ebrio de cielo y era en manos del indio de las islas, la aleta de un lobo de mar; hoy la vela ávida de viento y la caña triunfadora.

¡Maulinos y chilotes, marineros del mar chileno, duros como los cerros y ágiles como las olas, vuestra es el ala del viento y vuestra el alma del mar!

Mares del sur, blanqueados por la nieve de antárticos plenilunios, mares de frías corrientes, ceñidos de ventisqueros y de islas, por donde cruzan a la deriva témpanos errantes, trozos del polo, y donde asoman su lomo las ballenas, pedazos de continente. 
Mar de los alacalufes y de los lobos bramadores, cuna de los vientos del polo que rompen el vuelo vencedor de los albatros y obligan al pingüino rey, inmovilizado en el hueco de las peñas, a apretar su huevo gris, en un trágico gesto de defensa, contra su pecho de seda, envoltura tibia de su corazón.

$\mathrm{Al}$ amparo de viejas velas, cangrejas húmedas de Chiloé o cuadras parchadas del Maule, he cruzado tu salvaje soledad, mar de los chilenos y he bebido tu hálito salino, hermano del puelche de las nieves y del acre aliento de los pehuenes.

\section{EL AGUILUCHO}

(Intermedio agreste)

Todas las mañanas, en un vuelo amplio y acompasado, como si se tratara de un ejercicio, descendía el aguilucho de los altos cerros y atravesaba el valle para ir a posarse en la rama de un viejo roble, al borde de una quebrada.

Era como un decorativo e imprevisto remate de aquel gajo carcomido, nostálgico de pájaros y vientos.

Inmóvil horas y horas, lucientes el blanco plumón del pecho y el oscuro terciopelo de las alas, descansaba el aguilucho de los cerros. En actitud avizora, la aguda cabeza rapaz.

Apenas su silueta era advertida por los pájaros, se producía en el aire un inusizado temblor de alas.

Volaban ruidosas las bandadas de jilgueros, las diucas desgranaban asustadas sus trinos de miel, alborotaban las tencas comadreras, tragábanse los matorrales el vuelo negro de los tordos, y lloicas y zorzales dejaban de cantar.

Sólo los tiuques, indiferentes, seguían sus vuelos cortos sobre los barbechos recién peinados por las rejas de luma. 
A cualquier alarma que el viento le trajese, alzaba de nuevo su vuelo de flecha, seguro y vertiginoso, y desaparecía.

A veces, quizá al aproximarse a un nido, lo seguían los pájaros del valle, y lo atacaban con denuedo. El, inmutable, limitábase a ascender cada vez más, en rápidos arcos de círculo, hasta que los pájaros abandonaban la persecución, y el aguilucho parecía disuelto en el aire, vibrante de sol.

Según los cabreros, en el hueco de un altísimo risco tenían su nido los aguiluchos de la montaña.

Nunca imaginamos que uno de ellos estuviera cerca de nosotros, que lográsemos observarlo con nuestros ojos ávidos y que pudiéramos tocar sus plumas con nuestras manos temerosas.

Era tan inaccesible para nosotros, como las nubes y las estrellas.

Una mañana, sin embargo, Juan Pechuga trajo al aguilucho de las alas, de las puntas de sus rémiges duras y frías como láminas de metal. Nuestro asombro no tuvo límites. Lo mirábamos perplejos, sin acertar a creer que aquel vuelo imponderable sobre el aire y la montaña estuviese aprisionado en la mano tosca como un pedrusco de Juan Pechuga.

El pájaro tenía un frío aspecto de hombre en desgracia. Sus ojos impenetrables parecían mirar por encima de nuestras cabezas. El corvo pico, de un azul de acero, era como el revólver posado en el velador de mi padre. Había en él una amenaza latente. Las fornidas garras se habían recogido como arañas friolentas.

El hecho se explicó, por fin, Juan Pechuga lo había visto, como siempre, parado en el roble viejo. Llevaba su honda de pastor en el bolsillo. Cogió una piedra y la lanzó sobre el árbol. El pájaro cayó, aturdido, a tierra. Juan Pechuga lo cogió de las alas'y lo observ6, sin encontrarle herida alguna.

-Durante el camino - decía sonriendo el cerruco- los pájaros parecían entonar un canto de alegría sobre su cabeza. Era más ruidoso el chillar de las diucas, más enfático el canto de las tencas charlatanas, más vivo el piar de los zorzales, entre el oloroso y nevado esplendor de los perales floridos. 
El pájaro fué amarrado de una pata, en el cuarto de las monturas, y allí, encaramado sobre el filo de un caballete, permaneció, día y noche manchando la penumbra del cuarto con el níveo blancor de su pecho. Era tan inmóvil su actitud, que no parecía vivo; sin embargo, al segundo día comió un trozo de carne, al tercer día le acercamos un zorzal. El pajarillo andaba a saltitos en las cercanías, sin que le inquietase su temible enemigo del aire. Tampoco el aguilucho parecía hacer caso de él.

Juan Pechuga, que conocía los grillos y los calabozos del retén de carabineros, explicaba el hecho con cierta tristeza sentenciosa:

-Es que está preso, patrón.

Muchas veces, furtivamente, penetramos al cuarto y aquellos dos puntitos brillantes y fijos de las pupilas, nos hicieron estremecer.

¿Era el misterioso enigma de los ásperos riscales, azotados por el viento, el que dormía en aquellos ojos redondos, inmutables?

Una mañana, algúien dejó abierta la puerta del cuarto de las monturas. En aquel rectángulo de luz, el aguilucho debió mirar un segundo perfil azul de los cerros lejanos, la clara luz que bañaba los valles y los lejanos bosques, donde, en esta época, volaría su pareja y arrastrando su ominoso cordel, el pájaro se lanzó hacia los cerros, recto como un proyectil.

Nosotros le vimos, con estupor, sobre nuestras cabezas, pero su vuelo no era el mismo. A pesar de su peso insignificante, aquella cuerda le impedía volar, lo atraía hacia la tierra, quebraba su vuelo dominador.

Se había producido el característico pavor entre los pájaros que, en un principio, volaron en todas direcciones, para retornar, rehechos, hacia el ave de rapiña. Tencas, zorzales, diucas y un tiuque lo acosaron de todas partes.

Era como si se hubiesen percatado de que las fuerzas y arrestos de su enemigo secular no eran los mismos.

El aguilucho se metió en la alba y olorosa pompa de un peral en flor, en el declive de la colina. Allí quedó prisionero, el cordel enredado entre las ramas. En balde agitaba sus rémiges de acero, cuando 
los pájaros, como un grupo de labriegos que persiguiesen a un ladrón, lo picoteaban sin piedad.

Una tenca le partió un ojo, un tiuque, el otro, y agonizante, quedó sujeto de uno de los gajos, colgantes las alas y lacia la cabeza dominadora.

Una lluvia de pétalos olorosos, con pintas de sangre, rodó sobre la tierra oscura.

- Lo mismo cayó cuantu'ha el negro Manuel, observó Juan Pechuga, recordando la historia de un célebre salteador de Peñalquín.

Luego, con ruidoso aleteo, los pájaros se dispersaron por el campo.

Alrededor del aguilucho agonizante, sólo vibraba la sordina de miles de abejas, que volvían de nuevo a las flores de primavera.

Era la época de las semillas y de los almácigos. Los pájaros audaces caían en racimos sobre las eradas de cebollinos y betarragas.

Entonces, Juan Pechuga concibió la gran idea. En lugar del harapo ya desacreditado que servía de espántajo en la ladera, colocó al aguilucho, sujeto por las puntas de las alas a un madero horizontal que giraba sujeto con flexibles correas, alrededor de un hualle clavado en la tierra.

El viento movía el cuerpo del aguilucho, dando la sensación de la vida y tencas y zorzales, y tordos y diucas, rompían su vuelo al divisarlo, sin explicarse el prodigioso e inesperado fenómeno. 